J. Perinat. Med. 10 (1982) 85

\title{
A contribution to the monitoring of fetal arrhythmias
}

\author{
R. Boos, L. Auer, H. Rüttgers, F. Kubli
}

Department of Gynecology and Obstetrics, University of Heidelberg

Fetal heart rate monitoring combined with fetal ECG can supply valuable information concerning fetal status, especially in cases of fetal arrhythmias. The monitoring of fetal arrhythmias during the prenatal and intrapartum periods will be discussed with reference to the following case history.

\section{Case history}

The patient is a 31 years old gravida V, para III, with a history of incompetant cervix, diagnosed in the 16th week of pregnancy and treated by cerclage. An uncomplicated pregnancy ensued until a fetal arrhythmia resulted in the referral to our unit during the 36th week of pregnancy.

On admission, a satisfactory fetal heart rate tracing was not obtainable with the three non-invasive methods attempted. (DoPPLER ultrasound, phonocardiography, abdominal ECG) (Fig. 1).

Auscultation revealed a fetal rhythm of alternating bigeminy and trigeminy.

\subsection{Antepartum monitoring}

To obtain a tracing of the fetal arrhythmia, an electronical modification in the program of the HewletT PACKARD 8020 A cardiotocograph was necessitated. This modification was carried out as follows: the HP 8020 A has certain electronical components which monitor the input values and then eliminate values which fall outside of the preprogrammed parameters (description to follow). Interruption of these components caused elimination of these parameters, which then resulted in the acceptance of all incoming values for fetal heart rate.

\section{Curriculum vitae}

Dr. med. RAINER BOOS, born in 1947. Studied in Heidelberg and was graduated from the University of Heidelberg in 1974. 1975 Internship. Since 1976 he is working as resident in the department of Obstetrics and Gynecology of the University of Heidelberg. Field of interest: Fetal monitoring.

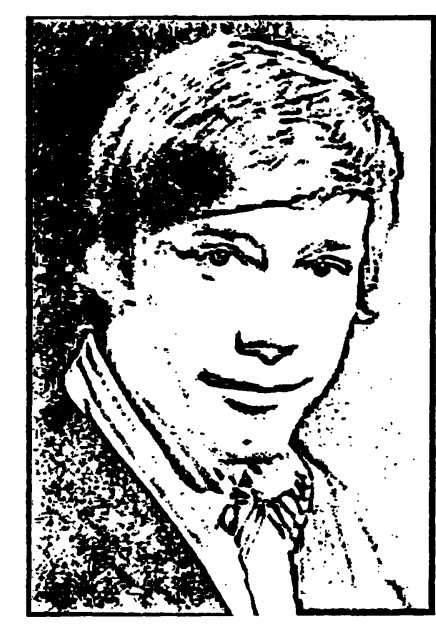

This modification in essence "turned off" the internal logic criterias. Continuous recording of the fetal heart rate, varying between 60 and $120 \mathrm{bpm}$, was then made possible (Fig. 2).

The exclusion of artefacts (e.g. alternating registration of maternal and fetal heart rate) was elicited by simultaneous fetal abdominal ECG monitoring (Fig. 3). This confirmed the bigeminal or trigeminal rhythms diagnosed by auscultation.

The abdominal ECG did not allow for an exact diagnosis as to arrhythmia type because the $\mathrm{P}$-wave was hidden in electrical interference. The QRS interval was prolonged at 0.085 seconds (normal range: 0.04 to $0.06 \mathrm{sec}$.), which was interpreted as a sign of interventricular conduction delay.

A CTG was done at 2-3 days intervals, where the fetal heart rate was monitored with the internal logic of the HP 8020 A "turned off". The fetal arrhythmia persisted into the 38th week of pregnancy. 

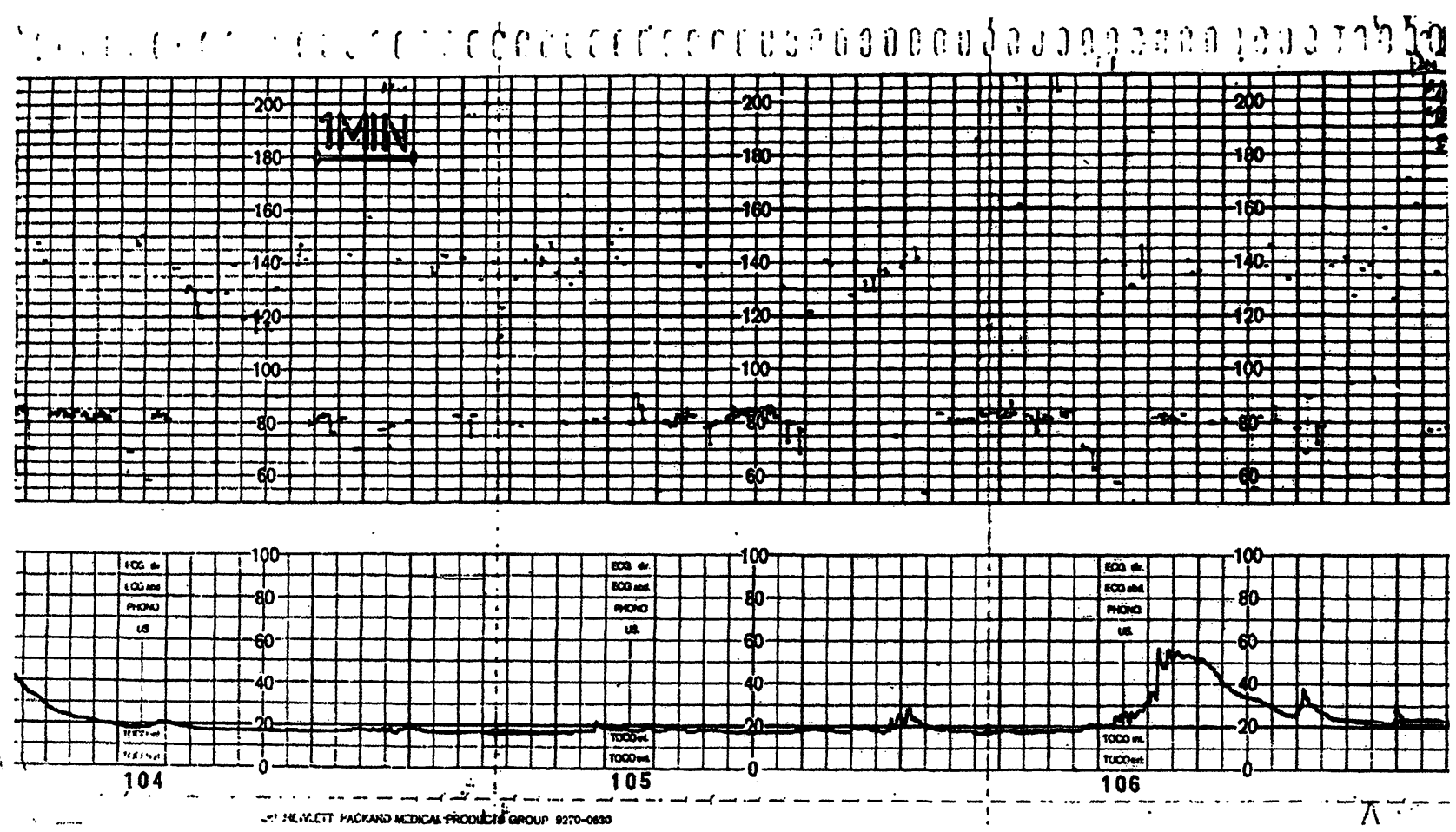

Fig. 1. Antepartal fetal heart rate curve in arrhythmia recorded on a conventional cardiotocograph. The same picture resulted in all conventional methods (ultrasound, phonographic, abdominal ECG). An interpretation of the curve is not possible.

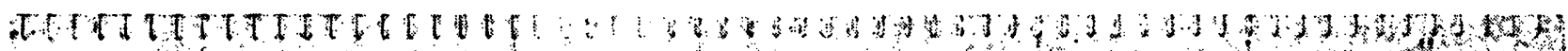

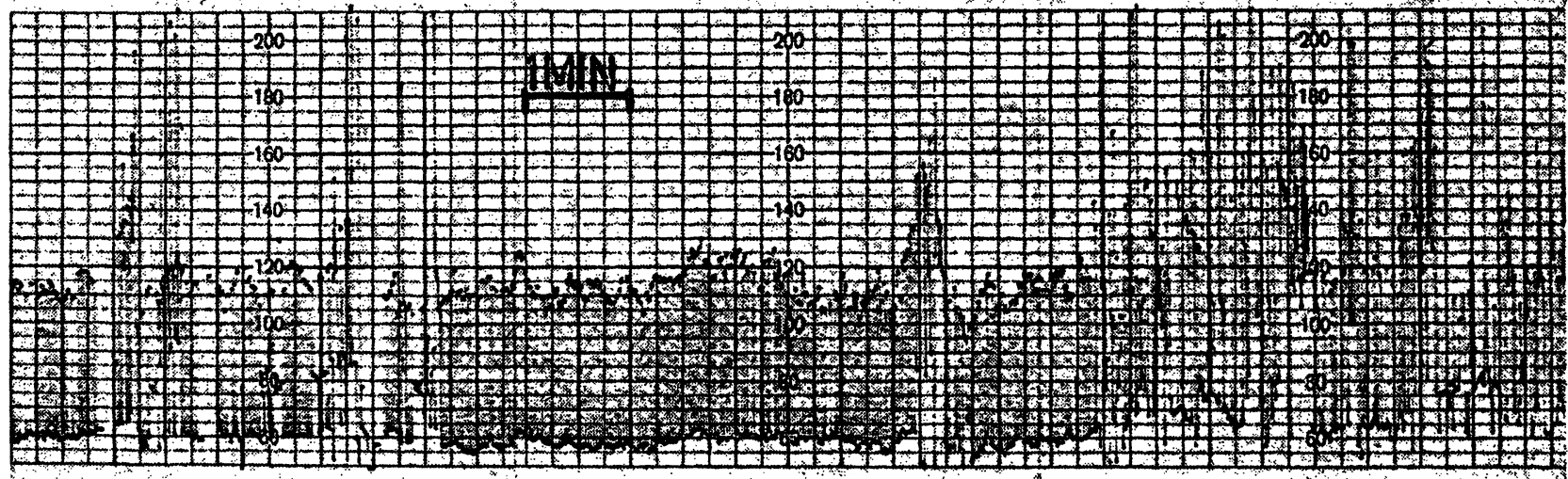

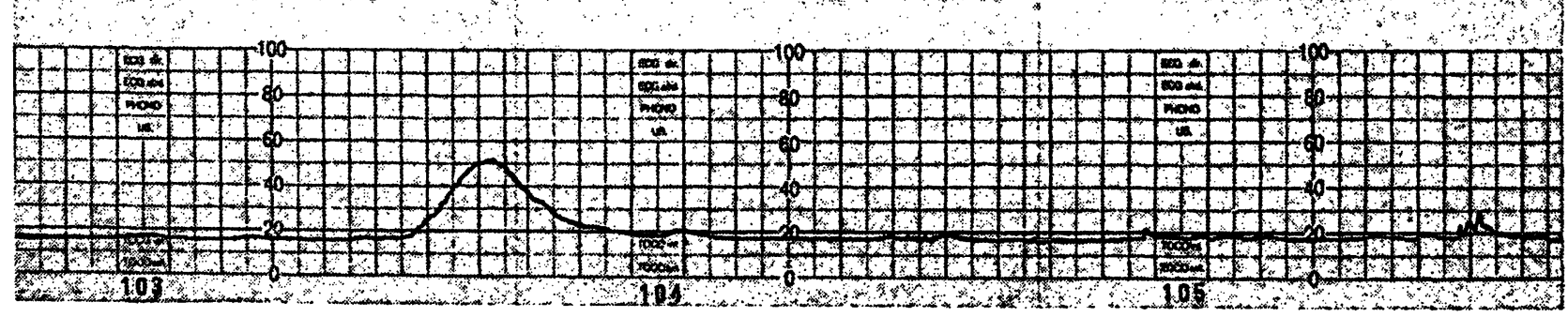

Fig. 2. Antepartal fetal heart rate recorded with ultrasound with instrument logic switched off. The arrhythmia is clearly to be seen in the middle part of the figure. The left and right part of the figure is disturbed by movement artefacts. 

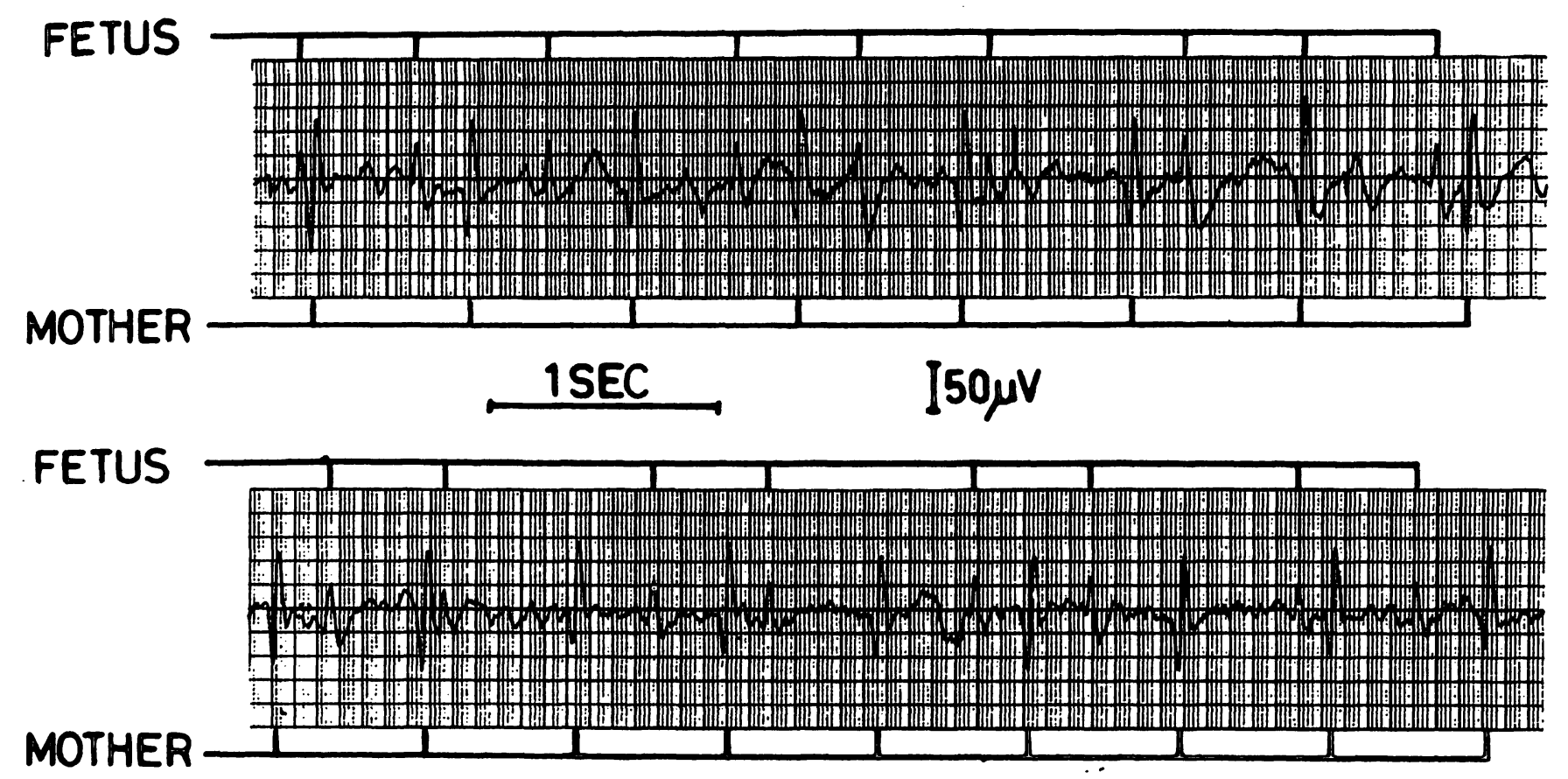

Fig. 3 The antepartal abdominal ECG clearly shows the bigeminal rhythms which can be heard by auscultation. Only the QRS complex is to be seen; other parameters such as the $\mathrm{P}$ or $\mathrm{T}$ wave cannot be recognized because of the superimposed disturbances.

\subsection{Intrapartum monitoring}

Labor was induced in the 38th week of pregnancy after lung maturity had been verified with an L/S ratio of 3.5 and the cervix was found favorable for induction. Fig. 4 shows the intrapartum CTG tracings registered directly via scalp electrodes with logic on (A) and logic off (B). (C) reveals the simultaneous recordings of the maternal cardiac rate.

Thus as shown, the mean fetal heart rate was $70 \mathrm{bpm}$ and the bradyarrhythmia became apparent only after the internal logic of the HP $8030 \mathrm{~A}$ had been turned off (Fig. 4b). Heart rate curves plotted via the fetal scalp ECG registered very few artefacts.

For this reason, some manufacturers have dispensed entirely with the internal logic in the direct cardiotocographic method (i.e. SIEMENS PARTECUST, COROMETRICS FM 112). In the instrument 8030 A from Hewlett PACKARd, the logic can be turned off via a switch for use in direct scalp CTG monitoring.

The fetal scalp ECG in our case history revealed an AV block with variable conduction (Fig. 5). Because of the atypical CTG pattern, several fetal scalp blood samples were obtained to assist in evaluation of fetal condition.

The intermittant MBA-pH measurements were supplemented by continuous subcutaneous tissue $\mathrm{pH}(\mathrm{tpH})$ measurements on the fetal scalp (RocHE $540 \mathrm{CTG} / \mathrm{pH}$ monitor) (Fig. 6).

A fetal hypoxia/asphyxia secondary to the fetal bradyarrhythmia could be excluded on the basis of the MBA pH or tpH values. A tissue $\mathrm{pH}$ of 7.24 corresponds to the initial value of the microsample $\mathrm{pH}$ of 7.29. The MBA $\mathrm{pH}$ did not change over a four hour period of labor $(\mathrm{pH}=7.30)$, whereas the tissue $\mathrm{pH}$ fell a short time before delivery from the initial value to a tpH of 7.18, a drop of 0.6 units. The tissue $\mathrm{pH}$ is closely correlated with the umbilical arterial $\mathrm{pH}(\mathrm{UApH}=7.20, \mathrm{tpH}=7.18)$, and the capillary MBA pH is closely correlated with the umbilical vein $\mathrm{pH}(\mathrm{UVpH}=7.29, \mathrm{MBUpH}=$ 7.30).

The fetal arrhythmia with varying frequencies is not detected by the CTG $\mathrm{pH}$ monitor. An extreme fetal bradycardia is falsely registered at normal tissue $\mathrm{pH}$ values (Fig. 6).

Fig. 7 gives an overall view of the antepartum and intrapartum devices. 

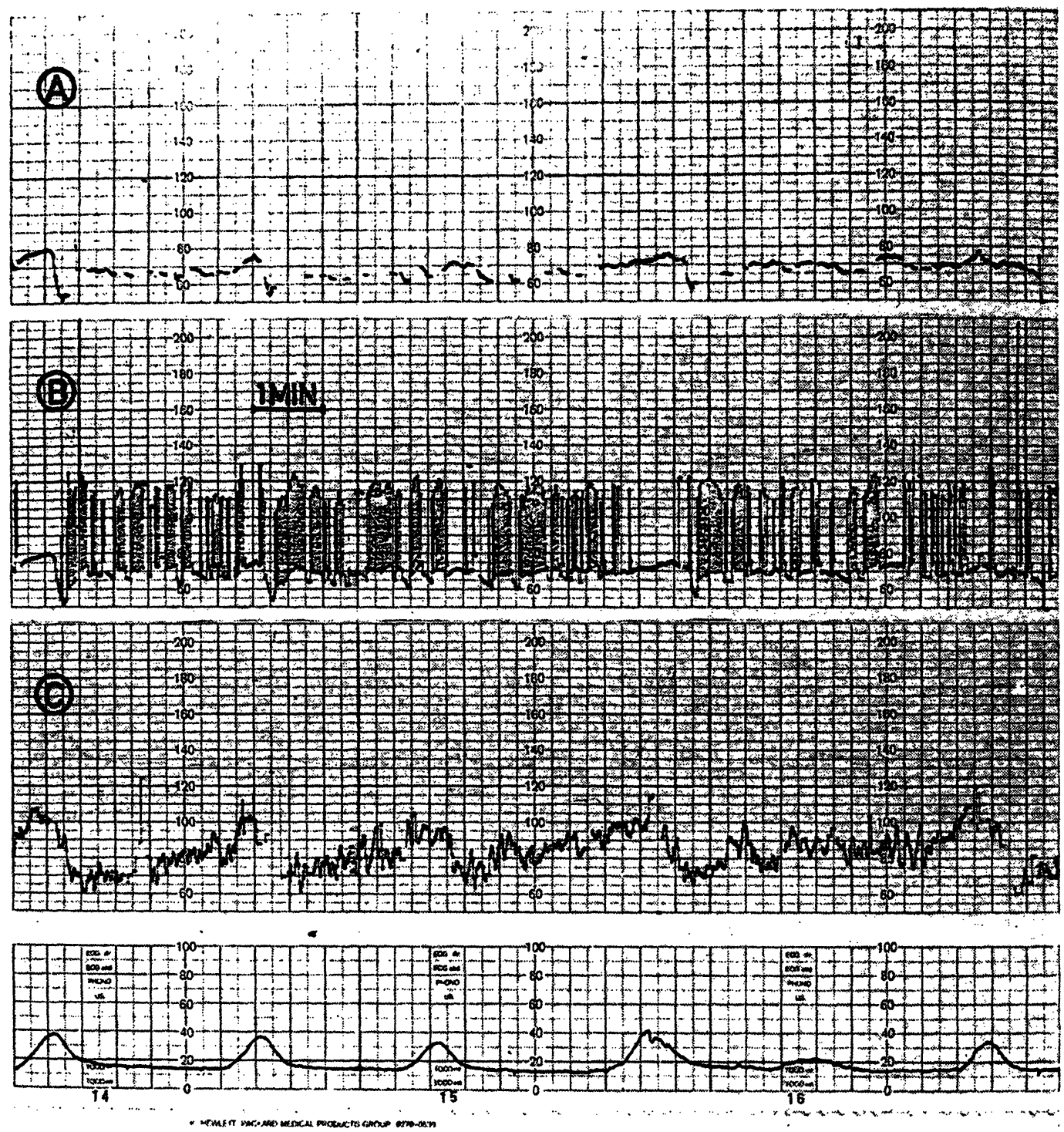

Fig. 4. A shows the heart rate curve registered during labor with instrument logic switched on.

B shows the same curve with instrument logic switched off. Here the arrhythmia present is clearly detected.

C simultaneously with fetal heart rate, the maternal heart rate was also registered. In this way, the possibility can be excluded that the maternal heart rate was registered in the bradycardiac phases of the arrhythmia.

\subsection{Neonate}

The $2850 \mathrm{~g}$ male newborn (arterial $\mathrm{pH}=7.20$, venous $\mathrm{pH}=7.29$, APGAR 9/9/10) was transferred to the Dept. of Pediatrics because of a persistent bradycardia. Here the newborn showed AV-blocks varying from $1^{\circ}-3^{\circ}$ with the development of cardiac insufficiency. At first, suspicion of a ventricular septal defect was expressed, but cardiac catheterization did not reveal an organic heart defect. The child was kept for further observation in the pediatric cardiac division.

\section{Discussion}

In most cases of fetal arrhythmias, a technically satisfactory and interpretable continuous registration of heart rate is hardly possible. The diagnosis is made by auscultation. According to KoMÁROMY [3], the most frequent fetal arrhythmias are extrasystoles and atrioventricular conduction disorders.

The problems of monitoring fetal arrhythmias are discussed by way of the previous case history of a fetal AV block. 


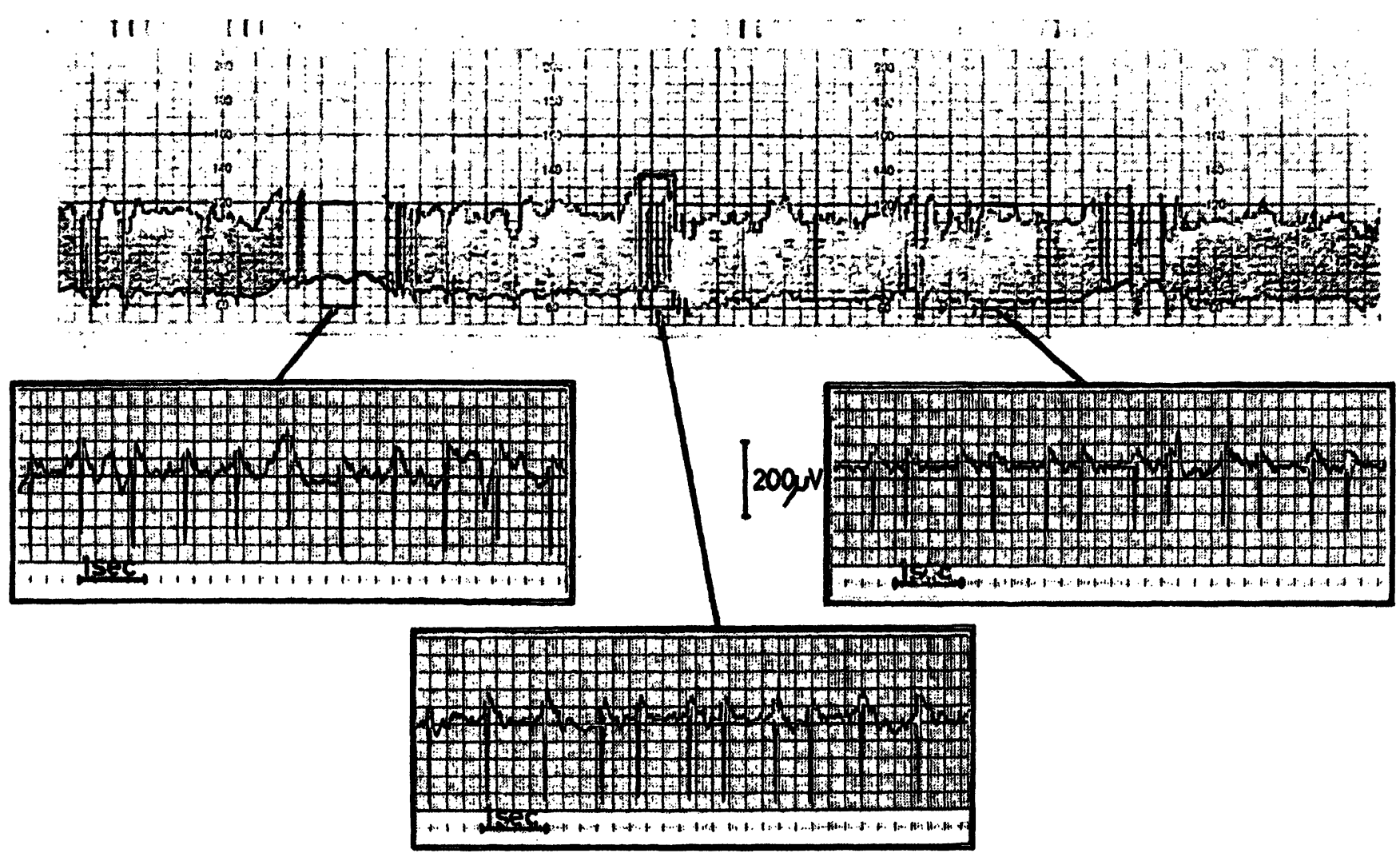

Fig. 5. The assignment of the intrapartally recorded heart rate patterns to the corresponding ECG complexes is shown. An AV block I-III could be diagnosed on the basis of the ECG complexes.

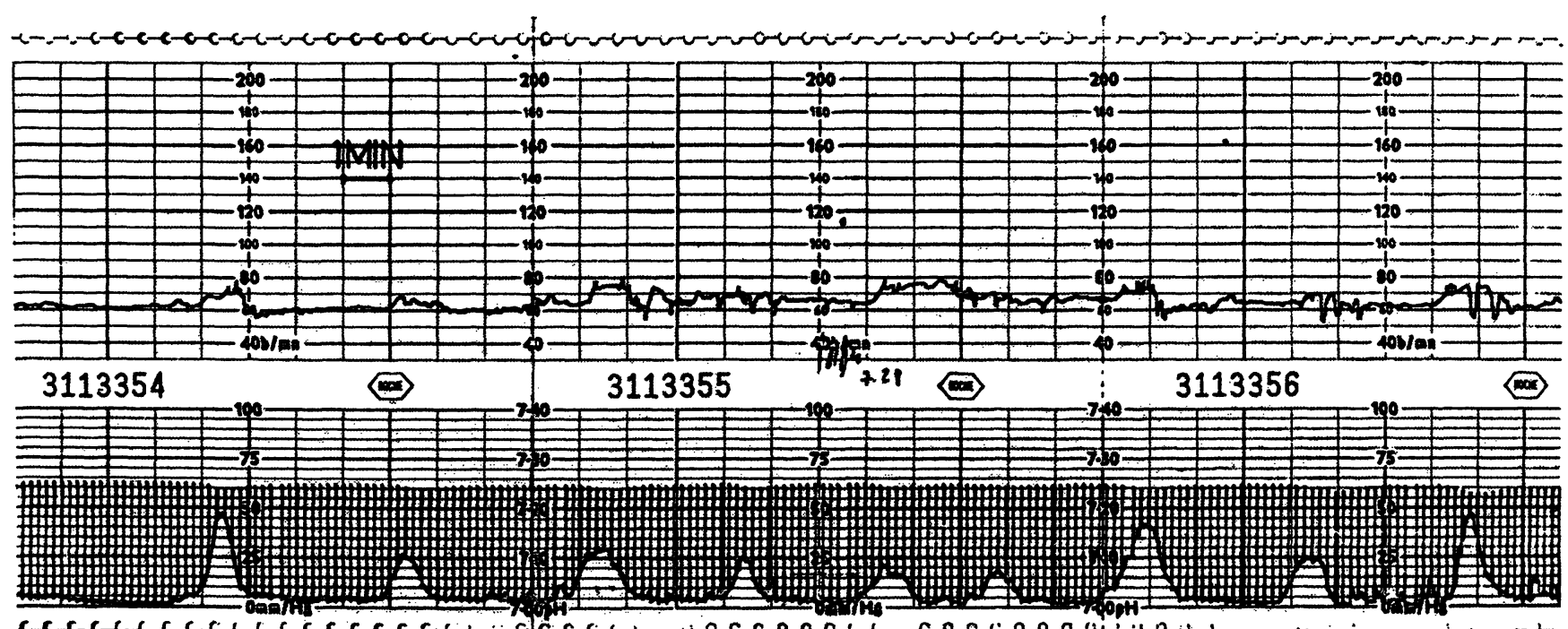

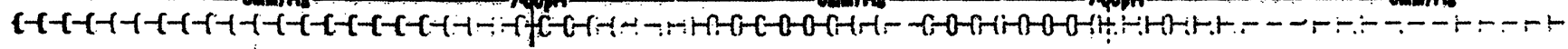

Fig. 6. In the lower part of the figure, the labor curve together with the subcutaneous tissue pH values measured on the scalp is to be seen. An application of the $\mathrm{pH}$ electrode is always worthwhile when an interpretation of the heart rate curve in the conventional sense is not possible.

The heart rate curve recorded by the Roche tocograph in the upper part of the figure falsely registers a pronounced brady cardia, cf. also Fig. $4 b$. 

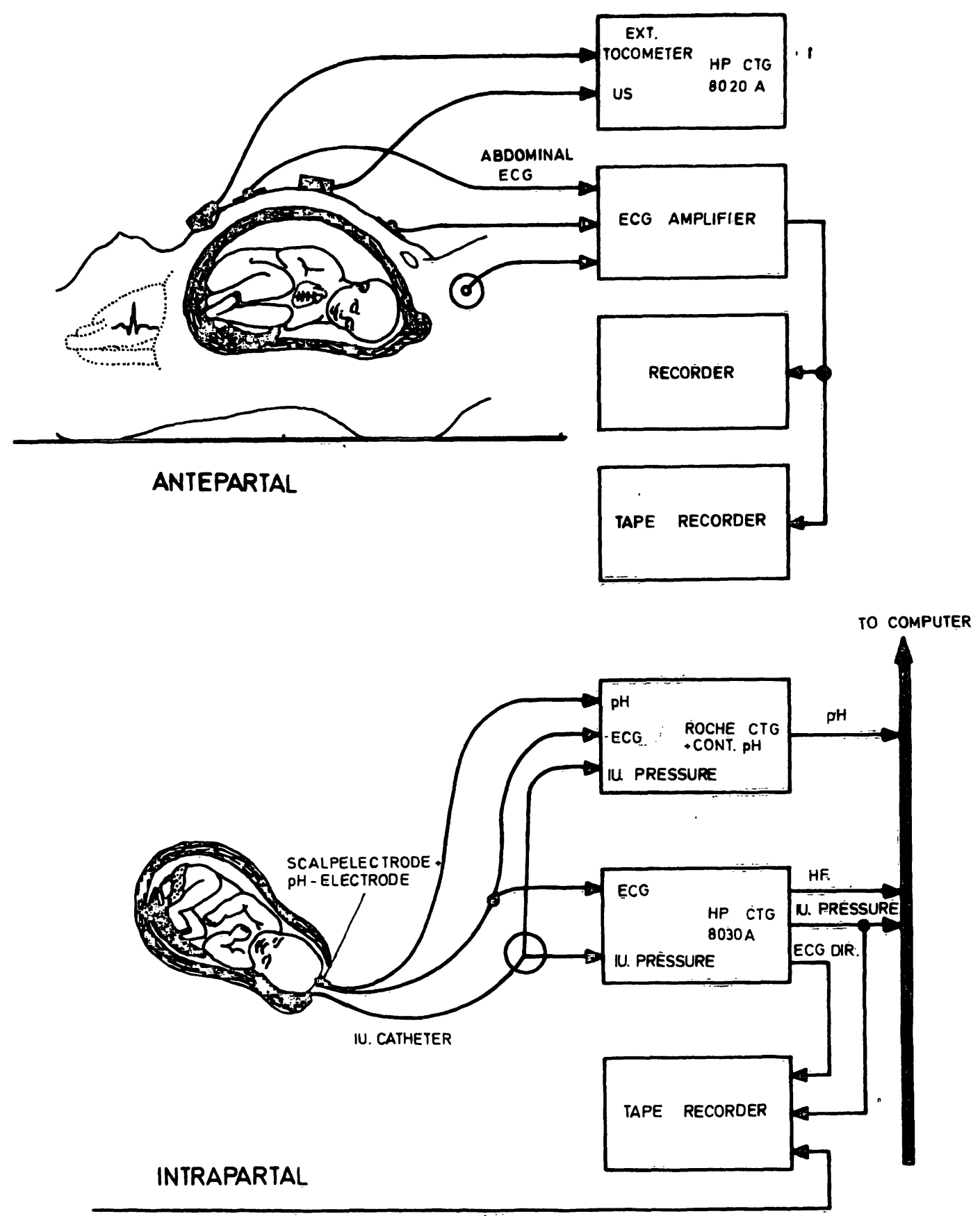

MATERNAL ECG

Fig. 7. Schematic representation of the antepartal and intrapartal monitoring of the arrhythmia described. Antepartum period. Schematic representation of antepartum monitoring apparatus. HP 8020 A receives input from US (ultrasound heart rate monitor) and ext. tocometer. Simultaneous fetal abdominal ECG monitoring is amplified and recorded. Above data were stored on tape for documentation purposes. Intrapartum period. Schematic representation of intrapartum (direct) monitoring apparatus. Roche monitor receives input from continuous tpH measurement, ECG monitor and intrauterine pressure. HP CTG 8030 A receives ECG and intrauterine pressure input. Simultaneous maternal heart rate is monitored. Above data were also stored on tape and analysed by computer.

\subsection{Congenital AV block}

During pregnancy and labor, persistent fetal bradycardia without signs of hypoxia indicates the possibility of a congenital AV-block. According to
GOCHBERG [2], this condition has an incidence of 1 in 22000 live births. About 40 cases of AV conduction block, diagnosed antepartum, are reported in the literature [8]. Congenital heart malformations were found in about $40-50 \%$ of the cases. If 
no structural lesions are present the prognosis is good.

Apart from frequent prenatal visits, answering parental questions about fetal cardiac defects and informing the pediatrician about the predicted date of delivery, further clinical consequences are not expected.

Congenital conduction disorders without cardiac malformations usually regress within days or weeks with normalization of heart rate.

\subsection{Monitoring problems}

\subsubsection{Antepartum period}

Fetal arrhythmias are discovered mainly by auscultation or via the "audio" output of the cardiotocograph. An interpretable heart rate curve can often not be obtained. In terms of differential diagnosis, the possibility of false registrations due to trigger uncertainties or maternal signal artefacts must be considered [5].

With the instrument logic criterias turned off and true beat-to-beat registration, the arrhythmia can be demonstrated by way of the heart rate curve.

In contrast to the direct (intrapartum) monitonng, where many commercially available cardiotocographs posses the capability to turn off the internal logic, only one monitor with the same capability exists for external (antepartum) use, as far as we know (Corometrics FM 112). All others require electronic manipulation to "turn off" the internal logic criteria.

Another noninvasive technique (computation of systolic time intervals of the fetal cardiac cycle) to evaluate the cardiovascular performance of arrhythmic fetuses antepartum is described by SCHLOTTER [6].

\subsubsection{Intrapartum period}

Cardiotocographs with the capability of having the internal logic criterias turned off should be used for continuous monitoring of fetal bradyarrhythmias during delivery.

Since the exact detection of fetal heart rate is important in fetal arrhythmia, some explanation as to the way in which the cardiotocograph works is required:
The internal logic monitors the beat-to-beat change of the incoming heart rate. If this change falls outside of predetermined criteria, usually $\pm 14 \mathrm{bpm}$ or $\pm 28 \mathrm{bpm}$, this value is rated as an artefact, disregarded, and the previous value used (halt phase). Thus, an arrhythmia with the logic criteria on is not detected. Instead, a continuous heart rate curve with occasional halt phases is recorded. It is also possible to record a nonexistent bradycardia.

If (as in the present case) an arrhythmia with periodic beat-to-beat alterations is involved, then the two heart rate values have the same priority; the instrument logic thus cannot make any distinction for one of the frequency values. As a result, no registration takes place in such cases. In the cardiotocograph of the $\mathrm{pH}$ monitor (Fig. 6), in this case it is always the lower heart rate value which is detected as correct. The frequency jump which follows it (ca. 40-60 bpm) is regarded as an artefact; the instrument then goes into a halt phase. The following value is then a jump to the lower heart rate again, which is regarded as correct by the cardiotocograph. A constant alternation between registration and halt phase thus takes place here. In consequence, a bradycardia is falsely recorded because this instrument logic always decides only for the lower heart rate value.

During labor a persistent bradycardia must arouse suspicion that the maternal heart rate is being picked up through the fetal scalp electrode. Simultaneous maternal heart rate monitoring should be used to exclude this possibility.

The nature of the fetal arrhythmia can be recognized via the directly registered fetal ECG (Fig. 5), since all ECG complexes are detected. This can be of importance for postpartum neonatal management.

Since the CTG cannot be interpreted as usual during fetal arrhythmia, frequent scalp $\mathrm{pH}$ measurements must be performed to detect hypoxia as a possible cause or consequence of the bradyarrhythmia. Vaginal delivery is possible with normal $\mathrm{pH}$-values.

Additional information as to the fetal condition can be obtained by use of continuous subcutaneous tissue $\mathrm{pH}$ measurements (Fig. 6). However, as a method to detect compromised fetuses, this cannot yet be routinely used $[1,4]$. 
In our case, since the tissue $\mathrm{pH}$ values changed only slightly during birth, we dispensed with more frequent scalp $\mathrm{pH}$ samples (once an hour). Just before birth, the tissue $\mathrm{pH}$ corresponded better to the umbilical artery $\mathrm{pH}$ than to the scalp capillary $\mathrm{pH}$.

\section{Summary}

-Antepartum and intrapartum monitoring problems are discussed with reference to a case history of a fetal AVblock detected during the 36 th week of pregnancy. CTG instruments where the internal logic criteria can be turned off are suitable for monitoring arrhythmias. During labor the direct fetal ECG permits exact diagnosis as to the type

of arrhythmia. The necessity of antepartum diagnosis in regard to postpartum pediatric management and hypoxic states during labor justify the large expenditure on monitoring apparatus. During labor continuous tissue $\mathrm{pH}$ measurement via the fetal scalp give added information as to fetal condition.

Keywords: Antepartum and intrapartum monitoring, fetal arrhythmia, AV-block.

\section{Zusammenfassung}

Ein Beitrag zur Überwachung fetaler Arrhythmien An Hand eines in der 36. SSW festgestellten fetalen A-VBlockes wird die Problematik der ante- und intrapartalen apparativen Überwachung erörtert. Zur ArrhythmieÜberwachung sind CTG-Geräte geeignet, bei denen die logische Schaltung abgestellt werden kann. Die kontinuierliche Gewebe-pH-Messung am fetalen Skalp unter der Geburt gibt zusätzliche Informationen über den fetalen Zustand. Das direkte fetale EKG unter der Geburt erlaubt eine exakte Diagnose des Arrhythmietyps. Die Notwendigkeit der Diagnosestellung für die postpartalen pädiatrischen Maßnahmen sowie die Erkennung asphyxiebedingter fetaler Gefahrenzustände rechtfertigen den hohen apparativen Aufwand.

Schlïsselwörter: Apparative Überwachung antepartum und intrapartum, AV-Block, fetale Arrhythmie.

\section{Résumé}

Une contribution au monitoring des arythmies fétales Les problèmes de monitoring antépartales et intrapartales sont discutés en se référant à un cas d'un bloc $\mathrm{A}-\mathrm{V}$ fétal trouvé pendant la 36 semaine de grossesse.

Les appareils CTG présentant la possibilité de couper les contacts logiques internes sont appropriés pour la surveillance des arythmies.
Pendant le travail, l'ECG fétal direct permet une diagnose exacte du type d'arythmie. La nécessité de la diagnose antépartale en regard du traitement pédiatrique et la reconnaissance des états hypoxiques durant le travail, justifient les larges dépenses d'appareils de monitoring. Durant le travail la mesure continue du pH-tissulaire via le crâne fétal donne une information supplémentaire sur la condition fétale.

Mots-clés: Arythmie fétale, monitoring fétal antépartale, monitoring fétal intrapartale.

\section{Bibliography}

[1] Boos, R., H. RÜTtgerS, D. MUliawAN, D. HEINRICH, F. KUBLI: Continuous measurement of tissue $\mathrm{pH}$ in the human fetus. Arch. Gynecol. 226 (1978) 183

[2] GOCHBERG, S. H.: Congenital heart block. Amer. J. Obstet. Gynec. 88 (1964) 238

[3] KOMÁROMY, B., J. GAAL, L. LAMPE: Foetal arrhythmia during pregnancy and labour. Brit. J. Obstet. Gynaec. 84 (1977) 492

[4] KUBLI, F., H. RÜTTGERS, K. WERNICKE (eds.): Proceedings of the first international workshop on tissue $\mathrm{pH}$ measurements in obstetrics. Arch. Gynecol. 226 (1978) No. 1-2

[5] RÜTTGERS, H.: Technik, Registrierungsprinzipien und Registrierfehler von Kardiotokographen. In: FISCHER, W. M. (ed.): Kardiotokographie, Lehrbuch und Atlas. Thieme, Stuttgart 1976
[6] SCHLOTTER, C. M.: Antepartale nichtinvasive Abklärung peristierender Rhythmusstörungen des fetalen Herzens Geburtsh. u. Frauenheilk. 41 (1981) 32

[7] SHENKER, L.: Fetal electrocardiography. Obstet. Gynecol. Surv. 21 (1966) 367

[8] SHENKER, L.: Fetal cardiac arrhythmias. Obstet. Gynecol. Surv. 34 (1979) 561

[9] STAMM, O. .U. LATSCHA, P. JANECEK, A. CAMPANA: Kontinuierliche $\mathrm{pH}-\mathrm{Messung}$ am kindlichen Kopf post partum and sub partu. Z. Geburtsh. Perinat. 178 (1974) 368

Received May 12, 1981. Accepted January 27, 1982.

$$
\begin{aligned}
& \text { Dr. med. Rainer Boos } \\
& \text { Universitäts-Frauenklinik } \\
& \text { Voßstraße } 9 \\
& \text { D-6900 Heidelberg FRG }
\end{aligned}
$$

